\title{
Managerial attitudes towards the incompleteness of performance measurement systems
}

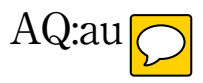

\author{
Syrus Islam \\ Auckland University of Technology, Aukland, New Zealand \\ Ralph Adler \\ Department of Accountancy and Finance, University of Otago Dunedin, \\ New Zealand, and \\ Deryl Northcott \\ Auckland University of Technology, Aukland, New Zealand
}

Performance measurement systems

\begin{abstract}
Purpose - Performance measurement systems (PMSs) are at the heart of most organisations. The aim of this study is to examine the attitudes of top-level managers towards the incompleteness of PMSs.

Design/methodology/approach - This paper draws on an in-depth field study conducted in an energy and environmental services provider based in New Zealand. The data obtain $\mathrm{c} m 20$ semi-structured interviews were triangulated against on-site observations and company document $\Omega$

Findings - The findings suggest that whether the incompleteness of a PMS is considered problematic or non-problematic depends on the role that the PMS plays in implementing a firm's strategy. The authors show that when the PMS is mainly used to trigger improvement activities on and around strategic objectives, and managers perceive adequate improvement activities to exist and they consider the incompleteness of the PMS in relation to these strategic objectives non-problematic $\bigcirc$ ntrast, managers are concerned about the incompleteness of the PMS when an inadequate level of i rement activities is believed to exist around strategic objectives.

Originality/value - This study contributes to the nascent literature on managerial attitudes towards the incompleteness of PMSs by identifying conditions under which the incompleteness is considered problematic or non-problematic. The authors also contribute to the literature on the association between design qualities of PMSs and firm performance by suggesting that poor design qualities of a PMS (such as incompleteness) may not always translate into poor firm performance.
\end{abstract}

Keywords Performance measurement systems, Strategy, Performance metrics, Incompleteness, Managerial attitudes, Design qualities

Paper type Research paper

\section{Introduction}

Performance measurement systems (PMSs) are at the heart of most organisations and should be designed to reflect organisational strategy (Chenhall, 2006; Hoque and Chia, 2012; Merchant and Van der Stede, 2012). While a wealth of literature exists on various design features of a PMS and their importance (Artz et al., 2012; Ferreira and Otley, 2009; Merchant, 2006), relatively little empirical research has sought to understand managers' attitudes towards the design features of PMSs in practice (Jordan and Messner, 2012).

PMS "incompleteness" refers to concerns with the representational qualities of performance metrics a PMS incorporates such as reliability, accuracy, precision, integrity 
and comprehensiveness (Jordan and Messner, 2012). The normative literature (Ittner and Larcker, 2003; Kaplan and Norton, 2001) argues that the incompleteness of a PMS is problematic because it can hinder strategy implementation and destroy organisational value by leading managers to pursue inappropriate goals and activities and/or by inhibiting them from pursuing appropriate goals and activities. The empirical research literature (Andon et al., 2007; Lillis, 2002) seems to support this normative view, with researchers finding that managers are concerned about the incompleteness of PMSs and that they endeavour to address this incompleteness by refining existing metrics and/or introducing new metrics.

However, some literature cautions against assuming that managers are necessarily concerned about the design features of accounting systems; instead suggesting the need to examine how managers actually use these systems in practice (Ahrens and Chapman, 2004; Chua, 1995; Hopwood, 1972). Indeed, a recent study suggests that, in practice, users are not always concerned about the incompleteness of performance metrics (Jordan and Messner, 2012), a suggestion we further examine and extend in the present study.

The prior PMS literature (Andon et al., 2007; Jordan and Messner, 2012; Lillis, 2002) has documented the attitudes of either designer-managers or user-managers towards the incompleteness of PMSs in a setting where superiors were designers and subordinates were users of the PMS[1]. However, designers and users of a PMS may be the same group (Lohman et al., 2004). Further, the investigated PMSs in the above stream of research were used to evaluate individual user performance. But a PMS can be used to review organisational performance only and not necessarily to evaluate individual user performance (FrancoSantos et al., 2012). This study focuses on investigating the attitudes of managers - who are both designers and users of their PMS - towards the incompleteness of a PMS that primarily measures organisational performance.

Research on the attitudes of managers towards the incompleteness of PMSs under these circumstances is important. When managers are both designers and users of a PMS that is not primarily used to evaluate individual user performance, they are likely to use the incomplete PMS in a flexible way due to the lack of evaluation pressure (Jordan and Messner, 2012). As a result, we might expect these managers to view the incompleteness of the PMS as non-problematic. However, the literature is largely silent on this issue. Hence, the question examined in this study is:

Q1. To what extent, and why, are managers, who are both designers and users of their PMS, concerned about the incompleteness of a PMS that primarily measures organisational performance?

We address this research question via an in-depth case study of an energy and environmental services provider. The findings of the study contribute to the literature in three ways. First, in contrast to the normative literature (Ittner and Larcker, 2003; Kaplan and Norton, 2001) and the prior research literature (Andon et al., 2007; Lillis, 2002), which suggest that the incompleteness of PMSs is problematic, this study shows that the incompleteness of PMSs is not always considered problematic in practice. These findings support and complement those of Jordan and Messner (2012) by specifying a novel condition under which the incompleteness of PMSs is considered problematic or non-problematic.

Second, the findings of this study suggest that the incompleteness (i.e. poor design qualities) of a PMS may not always translate into poor firm performance. As such, the current study contributes to the literature by suggesting a limitation to the findings of the previous studies (Cavalluzzo and Ittner, 2004; Verbeeten, 2008) that suggest that improved (poor) design qualities of a PMS are positively (negatively) associated with firm performance. 
Third, this study extends the prior literature on the incompleteness of PMSs (Giovannoni and Maraghini, 2013; Jordan and Messner, 2012; Lillis, 2002) by providing empirical evidence on the attitudes of senior managers - who are both designers and users of their PMS - towards the incompleteness of a PMS that mainly measures organisational performance. In doing so, this study also contributes to the PMS "domain theory" in management accounting research (Lukka and Vinnari, 2014, p. 1309).

The rest of the paper is structured as follows. Section 2 provides the literature review. Section 3 details the research methods. The empirical findings are then presented and analysed in Section 4. Section 5 provides a discussion of the main insights this study offers to the existing literature. The final section concludes and suggests avenues for future research.

\section{Literature review}

According to Jordan and Messner (2012), PMS incompleteness ranges from narrow to broad forms. Narrow forms of incompleteness concern the way in which performance metrics are measured or operationalised and pertain to the reliability, integrity, accuracy, robustness and precision of performance metrics (Jordan and Messner, 2012; Merchant, 2006). The narrow form of incompleteness can be solved by minor repair, for example, by changing the definition of and/or equation for performance metrics (Jordan and Messner, 2012).

On the other hand, broad forms of PMS incompleteness occur when "the outside reference point is so different from what the indicator stands for that incorporating it into the indicator is not possible" (Jordan and Messner, 2012, p. 550). That is, the broad form of incompleteness encompasses the question of comprehensiveness of performance metrics (Hall, 2008; Ittner et al., 2003)[2]. This form of incompleteness can be addressed by, for example, introducing an additional performance metric (Jordan and Messner, 2012).

It is well-established in the literature that performance metrics (or essentially any accounting information system) are intrinsically incomplete in that they cannot capture the total complexity of organisational life (Chapman, 1997; Giovannoni and Maraghini, 2013; Jørgensen and Messner, 2010; Wouters and Wilderom, 2008). For example, Wouters and Wilderom (2008, p. 491) maintain that "designing a perfectly complete PMS remains challenging, if not impossible, and would require nothing less than the expression of all relevant aspects of performance in quantitative terms".

Do organisational members consider the incompleteness of PMSs problematic? Organisational members' attitudes towards the incompleteness of PMSs can be addressed from two perspectives: designers and users of PMSs. Usually, superiors design a PMS (either incorporating or not incorporating subordinate feedback), whereas subordinates use it and are measured against the performance metrics it includes. In such a setting, designersuperiors may or may not consider the incompleteness of PMSs problematic, and if they do, they can address the incompleteness directly because they are likely to have such authority. On the other hand, user-subordinates may or may not also consider the incompleteness of PMSs problematic. However, if they consider it problematic, they are unlikely to have direct authority to address the incompleteness; rather, they may influence designer-superiors to address the incompleteness by lobbying or even by resistance.

A few recent studies have addressed, at least partially, the issue of organisational members' attitudes towards the incompleteness of PMSs. For example, Lillis (2002) investigated the perception of profit centre managers (i.e. designers) towards the effectiveness of multiple performance metrics designed to measure their manufacturing subunits' (i.e. users') performance. Drawing on data from 36 profit centre managers, Lillis

Performance measurement systems 
(2002, p. 511) showed that designer-managers were concerned about the incompleteness of metrics, as such incompleteness created problems in implementing the strategy:

The data [...] suggest that profit centre managers perceive less problems in managing the performance of cost centres when they are able to construct more complete measures of performance, and that they experience strategy implementation problems when measures are incomplete.

To address the incompleteness of metrics, designer-managers used various mechanisms such as the introduction of more innovative metrics, the integration of multiple existing metrics and the adoption of measurement weightings (Lillis, 2002).

In another study, Andon et al. (2007) showed that designer-managers in an Australasian telecommunications company introduced a PMS that mainly focused on time dimension and excluded other performance dimensions such as quality. Andon et al. (2007, p. 287) found that this one-dimensional PMS was considered incomplete and problematic by user-staff, as illustrated by a comment from a user-staff member:

There is way too much pressure because work conditions have become so unrealistic. We can't even fart without being timed. We are always interrogated about our time out of traffic. [...] We're told to end the call as soon as possible, so we basically are being asked to fob them off and say thank you for calling [Auscom]. How hypocritical is that? [...] I soon become to wonder myself if I am a person! I feel I get treated like a robot.

To relieve this pressure, user-staff engaged in subversive acts to game metrics and shared their dissatisfaction with the time-based metrics in various workshops (Andon et al., 2007). In an attempt to address the incompleteness of the PMS, designer-managers incorporated metrics related to the quality dimension of performance (Andon et al., 2007).

The above studies (Andon et al., 2007; Lillis, 2002) indicate that when superiors are designers and subordinates are users of PMSs, the incompleteness of PMSs is considered problematic by either superiors or subordinates. However, Jordan and Messner (2012) have recently qualified these findings. They found that operational managers (who were users of metrics) in an Austrian manufacturing company were sometimes concerned about incomplete metrics but at other times were not. The authors argued that when usermanagers can use the incomplete metrics in a flexible way (i.e. when metrics do not necessarily restrain their work), the incomplete metrics are not considered problematic. On the other hand, when designer-superiors impose evaluation pressures, the flexible use of metrics becomes difficult to sustain. Then, the incompleteness of metrics becomes a major concern because user-managers feel they need to see the effect of their activities on the metrics (Jordan and Messner, 2012). This work suggests that an incomplete PMS is not necessarily considered problematic in practice, a suggestion we further examine and extend in this study.

The purpose of a PMS can range from being used to plan and measure organisational activities (Franco-Santos et al., 2012) to forming the basis for organisational evaluation and reward (Jordan and Messner, 2012). In spite of Lohman et al. (2004, p. 277) describing how the senior supply chain management team at European Operations of Nike developed (with the help of the authors) a balanced scorecard-type PMS, which was "primarily" used by the senior management team "on a monthly basis to facilitate review of the organisation's performance", the extant literature principally adopts the perspective of a PMS as a system of evaluation and reward. As a consequence, evidence about the development and use of PMSs by senior managers to, for example, measure (but not evaluate) organisational performance is lacking. 
The PMS literature also commonly fails to recognise the full set of roles organisational members may assume relative to their respective organisations' PMSs. While it is true that in most instances, superiors are designers and subordinates are users of a PMS (as studied by Andon et al., 2007; Jordan and Messner, 2012; Lillis, 2002), there are occasions where a PMS's designers and users overlap (i.e. superiors are both the designers and users of a PMS). Prior research has neglected this possibility and chosen to treat the designer-superior and user-subordinate groupings as mutually exclusive. Accordingly, the literature has failed to address organisational members' attitudes towards incomplete PMSs when the designers and users are the same individuals, and this deficiency is especially evident where the PMS is used primarily to measure and improve organisational performance.

In summary, the literature has failed to distinguish organisational settings where PMS designers and users are the same individuals and failed to provide adequate representation of PMSs being used for measurement-only purposes. These are fundamental and conspicuous omissions. When managers are both designers and users of a PMS, they are unlikely to be coerced into a control system, which is a typical feature in a setting where superiors design and subordinates use the PMS (Adler and Borys, 1996). Further, when a PMS mainly measures organisational performance, typical individual user performance evaluation pressure is unlikely to exist. As a result, these managers are likely to use the PMS in a flexible way. Hence, following the argument of Jordan and Messner (2012), these managers are unlikely to consider the incompleteness of their PMS as problematic. However, little empirical research has sought to understand the attitudes of managers towards the incompleteness of a PMS under these circumstances. Extending previous studies and addressing this gap in the extant literature, we examine the attitudes of senior managers, who are both designers and users of a PMS, towards the incompleteness of a PMS that is used primarily to measure and improve organisational performance.

\section{Research methods}

This paper draws on an in-depth field study conducted in a single organisation. Because the aim was to explore, in an organisational context, managers' attitudes towards the incompleteness of PMSs, a field study approach was required.

Alpha, the case organisation, is a New Zealand-based energy and environmental services provider[3]. The company provides a wide range of services, including electricity generation, transmission and distribution to industrial and residential electricity users; electricity metering; solid waste management; infrastructure services to fibre optic asset management; and greenspace services. Alpha employs more than 500 employees and generates annual revenues of more than $\$ N Z 100 \mathrm{~m}$. The company had five departments Finance and Systems; Capability and Risks; Asset Management; Environmental Services; and Energy and Communications.

The research data were collected between December 2014 and November 2015 through interviews, archival records (both written and electronic) and informal meetings held on-site (e.g. in the company cafeteria) and off-site (e.g. at sponsored hospitality events). In qualitative field research, the aim of the researcher is to understand practices in their natural setting (Baker and Cohanier, 2014) and to "identify and include those actors and sources that can best inform the focus of their inquiries and produce the richest account of the phenomenon under investigation" (Parker and Northcott, 2016, p. 1116). In line with this, we sought to interview company members who were closely involved with the company's strategy and PMS development and implementation initiatives. At Alpha, the top management team was known as the executive leadership team (ELT), which comprised five senior managers: the chief executive officer; the chief financial officer; and the general managers of the Capability

Performance measurement systems 


\section{QRAM}

and Risks; Asset Management; and Energy and Communications departments. In addition to the ELT members, the business improvement and risk manager and the human resource manager were heavily involved in strategy and PMS development and implementation and were frequently invited to ELT meetings and other top-level operational meetings. All seven of these senior managers were interviewed for this study. Hence, research data were collected from everyone involved in the company's strategy and PMS development and implementation. In total, 20 semi-structured interviews were conducted; each interview lasted about $1 \curvearrowright$ pendix for interview questions).

Tabl rovides further details of the data collection. To preserve the anonymity of the interviewees, they are referred to as Senior Manager 1, Senior Manager 2 and so on. Extensive notes were taken during all interviews. When permitted, a digital voice recorder was used. The recorded data were subsequently transcribed and reread in conjunction with the detailed handwritten notes taken during the interviews.

One of the researchers spent four days per week on-site in the organisation from December 2014 until June 2015, then one day per week until November 2015. During this time, he was allocated a desk in the area occupied by the firm's managers from where he could observe their day-to-day working lives, including their reactions to various PMS metrics and results. This "peripheral member" level of participant observation (Adler and Adler, 1987), whereby the researcher takes no functional role within the organisation but nevertheless becomes assimilated within its day-to-day practices, helped to create an open and sharing interview context and gain the trust of company members (Akroyd and Maguire, 2011). It also facilitated access to various company materials such as confidential strategy and performance measurement documents and minutes of meetings. Further, spending a large number of working days at the company allowed the researcher to collect more nuanced data as he could see what the organisational members actually said and did (Jönsson and Lukka, 2007). Daily written notes were kept on all PMS-related discussions and activities observed while on site.

Consistent with prior studies (Ahrens and Chapman, 2004; Chenhall et al., 2010), the data were analysed following the recommendations of Eisenhardt (1989). This involved reviewing data (field notes, transcripts, documents) to identify common themes and unique insights in relation to managers' attitudes towards the incompleteness of the PMS at Alpha. These emerging findings were then compared with the existing research to identify similarities and dissimilarities with prior theory. In particular, any dissimilarities with prior theory were further investigated. This repeated iteration between the data, literature, and

\section{Interviews}

Chief executive officer

Chief financial officer

General manager, Capability and Risks

General manager, Asset Management

General manager; Energy and Communications

Business improvement and risk manager

Human resource manager

Table I.

Qualitative data gathering schedule
Documents

Strategy documents

Performance measurement documents

General company documents 
the research question was continued until a plausible fit among them was achieved (Ahrens and Chapman, 2006).

\section{Empirical findings and analyses}

\subsection{Alpha's strategy and strategic objectives}

A strategy can be either "intended" as it is developed deliberately, or "emergent" as it evolves over time (Mintzberg, 1978; Mintzberg and Waters, 1985). At the time of this study, there was no evidence of any emergent strategy existing at Alpha, as the organisation's intended strategy was recently established and retained currency in the organisation. The development of this intended strategy unfolded as follows.

Following an organisation-wide review in 2012-2013, the company exited from its property investments, water and civil construction businesses and emphasised its focus on the energy and environmental services sectors. In relation to this shifted business focus, Alpha developed its strategy as "incremental growth to [...] \$xxx million revenues with improved profitability, desired risk profile and increase in shareholder funds" (Principal Strategy, p. 9)[4]. The company broke down its strategy into 13 strategic objectives (Table II). Both the strategy and related strategic objectives were developed in the second quarter of 2014 at a workshop titled "Strategy Workshop". All interviewed senior managers participated in this workshop. Two senior managers recalled their experiences at the workshop as follows:

It was a high-level workshop. Following our major changes on the focus of business operations, we needed to develop a new strategy that would serve our purpose. So, we arranged a day-long workshop where we shared our thoughts. We also challenged each other. In the first session, we devised our [current] strategy. Then, [in the second session], we identified some key objectives to support our strategy. We can successfully deliver our strategy if we can successfully achieve these [strategic] objectives. (Senior Manager 2)[...]

Our [current] strategy and strategic objectives have come from our "Strategy Workshop". We held that workshop in June 2014. Our CEO, CFO, general managers, and some other key managers were invited [to the workshop]. We discussed what would be our strategy, considering our recent business shift. We decided that we want stable profitability but a low-risk profile. So, that was our strategy. Then we asked ourselves: How are we going to deliver our strategy? After a long session, we came to a consensus that we should stick to these 13 current [strategic] objectives. (Senior Manager 1)

\subsection{Alpha's performance measurement system and its development and use}

Prior to the development of its new strategy, Alpha had an "old" PMS, which mainly comprised financial performance metrics. But following the development of the new strategy, the old PMS was considered insufficient to reflect the updated strategy. Alpha's senior managers recognised that they should develop a new PMS that would allow the company to focus on both financial and nonfinancial performance, as both were considered important in delivering the updated strategy. A balanced scorecard-type PMS was perceived as ideal in this regard, as it was thought to provide a "balanced" focus on both financial and non-financial aspects of performance:

Our old measurement system had exclusively focused on financial metrics. But now we want to focus on both financial and nonfinancial sides. You will see that [now] we have many nonfinancial strategic objectives. These [nonfinancial strategic objectives] are important because performing well on them will help us to realise a better financial return. So, we had to devise a new measurement system. And, a balanced scorecard was an ideal one for what we were looking for 


\section{QRAM}

Strategic objectives

Deliver sustained profit

Grow third party revenue

Deliver the Beta ${ }^{\mathrm{a}}$ capital and maintenance works programme in full and on time

Hold or reduce fixed costs/indirect overheads as a proportion of total revenue

Develop a sustainable business improvement pipeline Complete regular audit and close-out action of all fatal safety risks

Reduce harm to people

Zero harm to public

Build organisational capability to support growth

Deliver a network more reliable than the regulated target

Deliver quality shared services that meet business requirements

Table II.

Alpha's strategic objectives and related performance metrics regulations
Metrics related to particular strategic objective

Net profit before tax

Return on funds used

Operating cash flow

Third party electricity revenue

Greenspace revenue

Solid waste revenue

Third-party revenue to total revenue ratio

IPM/AS handover to delivery on time

Funding approval for physical works

Physical works completion on time

No metric used

No metric used

Overdue audits and close out actions of all fatal safety risks

Lost time injury frequency rate (12 months rolling) [LTIFR]

Total recordable injury frequency rate (12 months rolling) [TRIFR]

High or critical severity public hazard incidents

Key vacancies

Variance to workforce plan

SAIDI [System average interruption duration index]

SAIFI [System average interruption frequency index]

Number of complaints

Enterprise application outages

Ensure full conformance with environment consents and Environmental consents and regulation breaches

Ensure conformity with the strategic risk register No metric used

Note: ${ }^{a}$ Beta (pseudonym) is Alpha's single biggest customer for its electricity services

[to implement the new strategy]. This allows a "balanced" focus on both [financial and nonfinancial] sides. (Senior Manager 2)

Hence, to better implement its updated strategy, Alpha introduced an almost brand-new balanced scorecard-type PMS in the third quarter of 2014. Alpha's PMS contained 21 performance metrics (Table II).

As for the strategy and strategic objectives, the PMS was developed jointly by all seven senior managers listed in Table I. However, in this case, two senior managers - the general manager (Capability and Risks) and the business improvement and risk manager - were the principal designers. These principal designers proposed the initial metrics, which were subsequently modified (where applicable) and approved in their current form (as presented in this study) by all seven senior managers:

They [principal designers] proposed a number of metrics initially and passed them to us for our feedback. In the next ELT meeting, we provided our feedback. After a minor change in a few of them [metrics], we decided that it was okay to start with [them]. (Senior Manager 5) 
At Alpha, the PMS measured the organisational performance rather than individual users' performance. Senior managers were the primary users of the PMS. At the weekly operational meeting, updates regarding PMS metrics and their associated activities were reviewed and discussed by senior managers. Although different senior managers were the "owners" of various metrics, they were not individually responsible for achieving the target for the metric. Achieving targets was not tied to any financial incentives, and missing targets was not considered to indicate poor individual performance by the senior manager who "owned" that metric. Rather, "owning" a metric meant monitoring the progress of that metric and its associated activities and providing updates in the weekly operational meeting. Achieving good results in relation to performance metrics was considered a collective responsibility:

I am the owner of net profit [before tax] and [operating] cash flow. Yes, you will see my name here [pointing to the PMS report] as the owner. [As the owner], I monitor what's going on around them [metrics] and report it to our weekly meeting. Then some [senior managers] say that we shouldn't do this and some say we should keep doing that. Eventually, we come to some sorts of agreement on what activities [associated with these metrics] we are going to continue and what we are not [going to continue], and whether we will be initiating any new activities [associated with these metrics]. So, yes, it is our collective duty to do well in net profit and cash flow. (Senior Manager 2)

This [the PMS] is not for evaluating our individual performance. Rather, [through the PMS], we review our overall [organisational] performance. We have targets [for PMS metrics], but no bonus for that [target achievement]. (Senior Manager 4)

Given the early stage of the (new) strategy implementation at Alpha, senior managers wanted to "get things started" (Senior Manager 7). Starting new initiatives on and around strategic objectives was considered more important than "measuring the output of the initiatives" (Senior Manager 7). In line with this, the main purpose of the PMS metrics was to prompt discussion and to initiate improvement activities on and around strategic objectives. As an example, a senior manager, who was the owner of the metric "greenspace revenue", explained how the discussion of this metric in a weekly operational meeting triggered relevant improvement activities:

In our last [weekly operational] meeting, we were concerned about activities associated with greenspace services. This is an emerging but important area that we must focus on if we have to grow our third party revenue [i.e. strategic objective 2]. We were particularly worried that we were not participating in all the bids that we could. So, we decided that we'll participate in as many bids as possible, even if we have little chance of winning. (Senior Manager 1)

To summarise, Alpha's senior managers were both the designers and users of the PMS. The PMS metrics measured organisational performance and were mainly used to prompt discussion in weekly operational meetings and trigger improvement activities on and around strategic objectives. Further, achieving metric targets was considered a collective rather than individual responsibility of senior managers. We argue that the way the PMS was used in the company influenced senior managers' attitudes towards the incompleteness of the PMS. This is elaborated next.

\subsection{Incompleteness of the performance measurement system considered problematic}

The incompleteness of some aspects of the PMS was considered problematic by Alpha's senior managers. The following section provides two examples.

4.3.1 Example 1. One of Alpha's strategic objectives was to "develop a sustainable business improvement pipeline" (Strategic Objective 5). The underlying intention of

Performance measurement systems 
developing this strategic objective was to deliver around $\$ \mathrm{NZ1.1m}$ value to the business via operational cost savings through the development and integration of various processes and systems:

The intent was that a key value driver in the business would be a continuous business improvement. We roughly indicated the desire to save 1 per cent of the total operational cost of the company, which was about $\$ 1.1$ million. Thus, through saving operating cost, we aim to generate value to the business. (Senior Manager 4)

However, there was no metric available to measure this strategic objective. For this reason, the PMS was recognised as incomplete (with respect to this strategic objective) by senior managers. This incompleteness was seen as problematic by senior managers:

Yes, we are not measuring this [strategic objective] and you can see the gap. (Senior Manager 1)

We don't have any measure for them. But [business improvement] activities are important for Alpha for margin and productivity. (Senior Manager 4)

Further comments by these managers revealed why this incompleteness of the PMS was perceived as problematic, i.e. because the lack of a metric to measure the strategic objective meant this aspect of performance escaped the attention of senior managers, resulting in inaction in regard to performance improvement:

[We could] reduce cost through appropriate procurement, improvement of productivity through improved IT systems, etc. [. . . ] Actually, we haven't decided yet about which project we will focus on. But it's an important area of our business where we are not doing much. (Senior Manager 1)

[These] activities are important for Alpha for margin and productivity. [...] A major focus of our future business is to increase productivity and it can be done through improving various systems and processes. [...] But, currently, we are way behind where we should have been. (Senior Manager 4)

Senior managers wanted to address this PMS incompleteness by introducing new metrics to trigger adequate improvement activities related to the strategic objective. For example, one senior manager commented:

We can measure "man-hours per unit revenue", which can be a proxy for productivity. [...] We can also use asset utilisation measures. We don't want to measure them only for measuring's sake. Rather, we want to do it for the real development purpose. We want to see that we are actually moving forward, not in terms of measuring activities but in terms of doing activities. What we need now is a push to think seriously about them [underlying improvement activities]. And, introducing metrics can give us that push. (Senior Manager 4, emphasis in original)

4.3.2 Example 2. At Alpha, one strategic objective was to "deliver a network more reliable than the regulated target". To measure this strategic objective, Alpha used three metrics (Table II), two of which - SAIDI and SAIFI measures of systems interruptions - are prescribed by the regulatory body. The Commerce Commission New Zealand (the government regulatory body for the electricity distribution industry) specifies regulatory targets for SAIDI and SAIFI. Companies that fail to meet these targets face a variety of sanctions. Some factors that contribute to SAIDI and SAIFI results are controllable by Alpha, such as poor network infrastructure. However, others are uncontrollable:

[... . there are many uncontrollable factors that frequently hinder the company's ability to achieve its target such as, for instance, rough weather and human activities. [. . .] [For example] there was a severe storm here on the 24th of May that cost us 29 minutes of disruption in one day. There 
was a $160 \mathrm{~km}$ [speed] wind and it took around two weeks to restore to normal conditions. So that kind of event we can't control. Other uncontrollable events include the pole hit by the truck driver. In many cases, we have little control over it. (Senior Manager 5)

The Commerce Commission also understands this issue. As SAIDI and SAIFI results are affected by uncontrollable factors, it makes allowances for companies after being satisfied via appropriate investigations. That is, usually, electricity distribution companies are punished for poor SAIDI and SAIFI results caused by controllable factors but not by uncontrollable factors:

[...] what they [the Commerce Commission] do is that they come in and investigate exactly the amount of outages that occurred. And then say: "that's okay, that [SAIDI and SAIFI caused by uncontrollable factors] is uncontrollable. So, we'll give [you] an allowance. But that [SAIDI and SAIFI contributed by controllable factors] was within your hands. Are you investing sufficiently to deliver a better quality network?" (Senior Manager 5)

However, Alpha was measuring SAIDI and SAIFI caused by both controllable and uncontrollable factors. This measurement practice did not provide Alpha with any opportunity to understand how much SAIDI and SAIFI resulted from controllable factors that could have been reduced by taking appropriate actions. SAIDI and SAIFI were thus constructed as being incomplete in this respect: "[Currently], they [SAIDI and SAIFI] don't show us how much we could control” (Senior Manager 4).

Senior managers considered this incompleteness problematic because they felt the company was failing to take adequate steps to manage controllable factors in relation to SAIDI and SAIFI. They considered refining these two metrics by splitting them into controllable and uncontrollable parts. The underlying motivation in refining the metrics was to have a better understanding of, and to track, the controllable factors and initiate appropriate improvement activities to reduce controllable SAIDI and SAIFI. That is, the aim of the senior managers was to trigger appropriate activities on and around this particular strategic objective by addressing the problematic incompleteness of the PMS:

I am thinking of updating these measures. [...] we have this now [pointing to the SAIDI and SAIFI charts on the wall of the training room]. We will do another chart here which will say "controllable SAIDI [and SAIFI]", and what we do about it. [...] We will put what is our controllable plan and how much we have done about that, and what actions we can take [to] reduce that [controllable SAIDI and SAIFI]. (Senior Manager 4)

In sum, the incompleteness regarding some areas of the PMS was considered problematic when senior managers felt that improvement activities related to the focal strategic objectives were inadequate. Then, senior managers endeavoured to refine existing metrics and/or introduce new metrics to promote adequate improvement activities around the strategic objectives concerned.

\subsection{Incompleteness of the performance measurement system considered non-problematic}

Alpha's senior managers regarded some aspects of their PMS non-problematic. The following two examples illustrate this.

4.4.1 Example 3. One of Alpha's strategic objectives was to "ensure conformity with the strategic risk register" (i.e. strategic objective 13). Adopting a lower risk profile throughout its operations was a key element of Alpha's strategy, which was also evident in the company's decision-making. For example, in 2012-2013, Alpha exited from its property development investments and its entire water and civil construction business. As noted in a key strategy document, "both decisions were taken to reduce the company's risk profile and
Performance measurement systems 


\section{QRAM}

exposure to volatile construction contracting and property investment markets and ensure profitability across all the trading divisions" (Principal Strategy, p. 4).

However, Alpha's PMS included no performance metric in relation to this strategic objective; so, the PMS was incomplete in this regard. Although senior managers acknowledged this incompleteness, it was considered non-problematic, as illustrated in the following interview quotations:

No, currently, we are not measuring anything in the scorecard [in relation to strategic risks]. But I am not worried about that, as we are initiating several activities [in this regard]. (Senior Manager \#1)

Risk management is a major focus of our business. We keep it at the centre of most business operations. [.. .] You will see we are doing a whole lot of stuff to deal with risks. [...] Yes, you are right it [a metric related to risks] is not on our Scorecard. We need to think: So what? That's a worthy question to ask. (Senior Manager 2)

In this example, the incompleteness of the PMS was considered non-problematic because senior managers believed that an adequate level of improvement activity was occurring around risk management. For example, as part of its "board meetings", the ELT prepared and reviewed reports on activities the company had undertaken to manage strategic risks. Such reports usually included the current and expected strategic risks, the level of risks and the company's actions or control plans regarding them (Figure 1).

Further, risk management was a key focus of top-level managerial meetings:

In most [of our] meetings, risk management is an important agenda item. So, for example, we had an "Executive Strategy Day", where the executive leadership team and some business managers participated. We discussed, among other [things], our current and future risk landscapes and, most importantly, how we are going to deal with them. [. . . The strategic risks are dealt with [by] the board [of directors] and ELT and, currently, we have 13 [identified strategic risks]. (Senior Manager 4)

Based on that review, both the format and content of Alpha's risk report were changed. Also, Alpha introduced an "operational risk register":

Recently, we have introduced an operational risk register to deal with more operational type risks. [The] operational risk register is online and can be viewed by managers and executives. It facilitates quick response by managers. (Senior Manager 4)

As senior managers believed that appropriate improvement activities were ongoing around risk management, they were not concerned about dealing with the incompleteness of the PMS by introducing new metrics, despite having direct authority to do so. It seemed senior

Figure 1.

An extract of an Alpha risk report

\begin{tabular}{|l|l|l|l|l|l|}
\hline Strategic risk & Context & Controls & Inherent & Residual & $\begin{array}{l}\text { Level of } \\
\text { control }\end{array}$ \\
\hline $\begin{array}{l}\text { Unexpected } \\
\text { significant loss } \\
\text { of revenue }\end{array}$ & $\begin{array}{l}3^{\text {rd }} \text { party business leads to } \\
\text { exposure to loss of a major } \\
\text { contract. [Client A] } \\
\text { procurement practices } \\
\text { changing for Green Space } \\
\text { and Waste. Smart meters } \\
\text { changing Retailer Services } \\
\text { landscape. Significance of } \\
\text { [Client B] contract. }\end{array}$ & $\begin{array}{l}\text { Contract management } \\
\text { and bid management } \\
\text { standards improving. } \\
\text { Close monitoring of } \\
\text { contract performance. } \\
\text { Relationship } \\
\text { management. Strategic } \\
\text { Review Committee. }\end{array}$ & Critical & High & Improving \\
\hline
\end{tabular}

Source: Company materials 
managers were unconcerned about addressing this PMS incompleteness as long as appropriate improvement activities were maintained regarding the focal strategic objective.

4.4.2 Example 4. Strategic Objective 9 was to "build organisational capability to support growth". The particular aspect of organisational capability that Alpha focused on was talent management - that is, it aimed to "attract, develop and retain talent" (Principal Strategy, p. 13).

In relation to talent management, Alpha used two metrics - key vacancies and variance to workforce plan (Table II). However, the metric "key vacancies" was incomplete in that there was no formal definition of a key vacancy. As a result, there was a degree of uncertainty in deciding what role would be considered as "key", as evidenced by these interview quotations:

There is no formal definition of it [key vacancies], but it has a significant role to achieve the strategic objectives of the business. Typically, a 'gardener' wouldn't be considered as a "key" vacancy because we can hire one easily. But a designer, line mechanic [or] engineer are considered key vacancies. Managers and supervisors are also considered key vacancies. (Senior Manager 6)

Probably [our] HR Manager determines whether it is a key vacancy. I haven't seen it written down. Strictly, what's key this week might not be key next week because the market conditions change. For example, some of the skill shortage in the market may no longer be considered a skill shortage. It is a little bit subjective, but when we say it is a key vacancy, we say only at that point of time. (Senior Manager 2)

It will be for a managerial position, a position with unique skill, and somebody hard to find. They [key vacancies] are the positions that the company can't afford to move on without. [...] There is no formal definition of key vacancies. (Senior Manager 3)

In addition to this lack of clarity around the definition, the two metrices associated with this strategic objective did not provide a comprehensive picture of talent management, as they overlooked some desired aspects of talent management such as developing current employees and sourcing new talent.

Although senior managers acknowledged this incompleteness, it was considered nonproblematic. For example, the lack of any formal definition of "key vacancies" caused little concern:

I would say it would be nice to have a [formal] definition of it [i.e. key vacancies]. But it's not a big issue. We have kind of an understanding [among us] about when we will consider a vacancy as a key vacancy. (Senior Manager 2)

Further, although Alpha's senior managers acknowledged the lack of existing metrics to provide a comprehensive picture regarding talent management, this was also not considered problematic:

Definitely, they [two existing metrics] don't say much about many aspects of talent management. But the good thing is that we do actually address them [i.e. various aspects of talent management] in our practice. I think the main issue is doing, not reporting [laughs]! (Senior Manager 6)

As reflected in the above quote, this incompleteness was considered non-problematic because several activities related to various aspects of talent management were ongoing within the company. For example:

To support our future business growth, we don't have any option other than nurturing and retaining our talent. So, we do various activities for that such as training - both in-house and outside, coaching, mentoring, and so on. We ensure that our employees get the opportunity to
Performance measurement systems 
develop their practical leadership skills and we have two major programmes: "The Way We Work" and the "Front-line Leadership Program". (Senior Manager 3)

Regarding sourcing talent, Alpha also undertook several activities and used multiple recruitment channels:

We also focus on whether we have flexibility in terms of sourcing suitable candidates. Because you know, if you don't have a good supply, you can't source people at the right time. So, we do advertise in Seek and Trade Me [local recruitment media]. [. . .] Many times we also ask some local recruitment specialists to find the right talent for us. Also, we do lots of offshore recruitment. (Senior Manager 3)

Also, most of the services that Alpha provided were on a contractual basis. So, the company recruited field-level workers mostly on a temporary basis (more than 50 per cent of its employees). Due to the nature of the work, there was high staff turnover and the company always seemed to be hiring. To manage this frequent and ongoing recruitment process, in 2014 Alpha started to use customised recruitment software, which was integrated into its existing software - SAP. The use of this customised software and its integration with the existing SAP facilitated the "organisation of the total talent management process a lot" (Senior Manager 3).

The above evidence reveals that a lot more talent management activities were ongoing in Alpha than were measured in the PMS, which is why managers seemed unconcerned about addressing the PMS incompleteness by refining existing metrics and/or introducing new metrics. The attitude of Alpha's managers appeared to be: As long as appropriate improvement activities are maintained around the strategic objectives, why worry about addressing the incompleteness of the PMS in relation to these strategic objectives?

\section{Discussion}

The case of Alpha illuminates top-level managers' attitudes towards, and reactions to, the incompleteness of PMSs. Specifically, this study provides a context-rich understanding of the attitudes of senior managers, who are both designers and users of a PMS that primarily measures organisational performance, towards the incompleteness of that PMS.

Within this organisation, senior managers were both designers and users of a PMS that was used to measure the corporate-level performance of the company. There was no (perceived) evaluation pressure on these senior managers in relation to the achievement of targets for the PMS metrics. Achieving metric targets was considered a collective responsibility of senior managers rather than an individual responsibility. Given the early stage of the company's strategy implementation, "getting things started" was considered more important than measuring the results of new performance initiatives. Accordingly, the PMS was used mainly to prompt discussion and to trigger improvement activities on and around strategic objectives. We suggest that the particular way the PMS was used in the studied company impacted senior managers' attitudes towards the incompleteness of this PMS.

At Alpha, incompleteness regarding some areas of the PMS was considered problematic only when an inadequate level of improvement activity was perceived to exist around the strategic objectives. In such cases, the incompleteness of the PMS focused senior managers' attention on understanding how performance improvement could be enhanced to better achieve strategic goals, and they then became concerned about addressing the PMS incompleteness by refining existing metrics and/or introducing new metrics. However, changing metrics was not motivated by a desire to overcome the incompleteness per se. 
Rather, it was seen as a means of triggering adequate improvement activities around the strategic objective concerned.

The PMS's incompleteness, however, was not always a cause for concern. In particular, in situations where Alpha's senior managers perceived appropriate improvement activities to exist, then PMS incompleteness was viewed as non-problematic. In such cases, senior managers did not endeavour to address the PMS incompleteness by refining existing metrics or introducing new metrics, although they had the direct authority to do so. Hence, the incompleteness of a PMS does not necessarily divert managerial attention away from achieving key strategic objectives, as the prior literature has suggested (Ittner and Larcker, 2003; Kaplan and Norton, 2001).

These findings contribute to the literature in three key ways. First, contrary to the normative literature (Ittner and Larcker, 2003; Kaplan and Norton, 2001) and prior research literature (Andon et al., 2007; Lillis, 2002), which suggest that the incompleteness of PMSs is problematic, our study suggests that the incompleteness of PMSs is not always considered problematic in practice. Rather, our findings indicate that when managers perceive adequate improvement activities to exist around the focal strategic objectives, they consider the incompleteness of a PMS in respect to these strategic objectives non-problematic.

These findings also support and extend those of Jordan and Messner (2012) by highlighting particular conditions under which incomplete performance metrics are considered problematic or non-problematic. Jordan and Messner (2012) show that when superiors are designers and subordinates are users of a PMS, the incompleteness of the PMS is not always considered problematic. They suggest that the incompleteness is considered:

- non-problematic by users when they can use performance metrics in a flexible way; and

- problematic when users cannot use metrics in a flexible way due to evaluation pressure imposed by designer-superiors.

Our study extends these findings by demonstrating that, even when users can use PMSs in a flexible way, and even when there is no typical evaluation pressure in relation to the achievement of metrics' targets, the incompleteness of PMSs may still be considered problematic.

Specifically, our findings suggest that whether the incompleteness of a PMS is considered problematic or non-problematic depends on the role that the PMS plays in implementing an organisation's strategy. We show that when the PMS is mainly used to trigger improvement activities on and around strategic objectives, the incompleteness of the PMS is considered:

- non-problematic when managers believe adequate improvement activities around strategic objectives are ongoing; and

- problematic when managers believe an inadequate level of improvement activities exists around strategic objectives.

Cavalluzzo and Ittner (2004) suggest that the use of ambiguous and difficult to capture metrics is negatively associated with perceived current and future benefits from performance improvement initiatives. In line with this, a recent study by Verbeeten (2008) shows that an increase in design qualities (e.g. clarity and precision of metrics) of PMSs is associated with high firm performance. Together, these studies (Cavalluzzo and Ittner, 2004; Verbeeten, 2008) suggest that improved (poor) design qualities of PMSs are positively

Performance measurement systems 
(negatively) associated with firm performance. As a second contribution of our study, we point to a limitation to these findings by suggesting that poor design qualities in a PMS may not be always associated with poor firm performance. Rather, our findings suggest that when a PMS is mainly used to trigger improvement activities on and around strategic objectives, managers may remain unconcerned about addressing the incompleteness (i.e. poor design qualities) of a PMS if adequate improvement activities are perceived to exist around these strategic objectives. In such cases, although the PMS is incomplete, that is unlikely to have a negative impact on the firm's performance because underlying improvement activities to achieve the strategic objective(s) are in place. Indeed, these performance improvement activities are likely to have a positive impact on the company's performance. Therefore, in such cases, the incompleteness of a PMS is unlikely to translate into poor performance.

While the typical PMS features superiors as designers and subordinates as users of the PMS, superiors can be both designers and users of a PMS (Lohman et al., 2004). Further, although a PMS is often used to evaluate individual user performance, it can also be used to measure organisational performance only (Franco-Santos et al., 2012; Lohman et al., 2004). The current study therefore makes a third contribution to the literature on the incompleteness of PMSs (Andon et al., 2007; Giovannoni and Maraghini, 2013; Jordan and Messner, 2012; Lillis, 2002) by providing empirical evidence on the attitudes of superiors, who are both designers and users of a PMS, towards the incompleteness of a PMS that measures organisational performance only. This study thus also contributes to "domain theory" in PMS research (Lukka and Vinnari, 2014, p. 1309).

\section{Conclusion}

The objective of this study was to investigate the attitudes of top-level managers towards the incompleteness of PMSs. Drawing on an in-depth case study, we find that managerial perceptions of, and reactions to, the incompleteness of PMSs depend on the role that a PMS plays in implementing an organisation's strategy. We show that when a PMS is mainly used to trigger improvement activities around strategic objectives, managers consider PMS incompleteness non-problematic as long as adequate improvement activities are maintained. We also find that these managers may not endeavour to address PMS incompleteness by refining existing metrics and/or introducing new metrics, even though they have direct authority to do so. In such instances, it does not appear that managers' tolerance of the known incompleteness of the PMS misdirects their managerial efforts away from strategic organisational objectives.

This study adopted a case study approach because it facilitated a rich understanding of the organisation's context, the way the PMS was used in the organisation, and managers' attitudes towards the incompleteness of the PMS. We acknowledge that managerial attitudes towards a particular organisational phenomenon can change over time (Jordan and Messner, 2012), so the same PMS incompleteness might be considered problematic at one point in time but non-problematic at another time. Therefore, further research is needed to explore whether and why attitudes of managers, especially those who are both designers and users, towards the incompleteness of PMSs could change over time. Further, a PMS can be built on various types of relationships, such as cause-and-effect, finality and logical (Islam, 2016; Malina et al., 2007); so, future research could explore whether and why managerial attitudes towards the incompleteness of a PMS vary when the relationships underpinning the PMS take different forms. Finally, future longitudinal studies could usefully examine the impact of PMS design, including incompleteness, on organisational performance. 


\section{Notes}

1. Making a clear-cut distinction between designers and users of a PMS is difficult because design and use activities of a PMS are often overlapping and iterative (Wouters and Wilderom, 2008). In this study, designers of a PMS refer to those organisational members who have direct authority to introduce and/or modify any parts of the PMS. On the other hand, users of a PMS are those organisational members who are primarily measured against and/or are the primary audience for the performance metrics it incorporates.

2. The comprehensiveness of PMSs refers to providing a broad set of performance metrics that supplements traditional financial metrics with a diverse mix of non-financial metrics and that are related to the important parts of the organisation (Hall, 2008; Ittner et al., 2003).

3. The original name of the company is disguised.

4. A major strategy document in the company. The original title of the document is disguised.

\section{References}

Adler, P.A. and Adler, P. (1987), Membership Roles in Field Research, Sage, Beverly Hills, CA.

Adler, P.S. and Borys, B. (1996), "Two types of bureaucracy: enabling and coercive", Administrative Science Quarterly, Vol. 41 No. 1, pp. 61-89.

Ahrens, T. and Chapman, C.S. (2004), "Accounting for flexibility and efficiency: a field study of management control systems in a restaurant chain”, Contemporary Accounting Research, Vol. 21 No. 2, pp. 271-301.

Ahrens, T. and Chapman, C.S. (2006), "Doing qualitative field research in management accounting: positioning data to contribute to theory", Accounting, Organizations and Society, Vol. 31 No. 8, pp. 819-841.

Akroyd, C. and Maguire, W. (2011), "The roles of management control in a product development setting”, Qualitative Research in Accounting \& Management, Vol. 8 No. 3, pp. 212-237.

Andon, P., Baxter, J. and Chua, W.F. (2007), "Accounting change as relational drifting: a field study of experiments with performance measurement”, Management Accounting Research, Vol. 18 No. 2 , pp. 273-308.

Artz, M., Homburg, C. and Rajab, T. (2012), "Performance-measurement system design and functional strategic decision influence: the role of performance-measure properties", Accounting, Organizations and Society, Vol. 37 No. 7, pp. 445-460.

Baker, R. and Cohanier, B. (2014), "What qualitative research can tell us about performance management systems", Qualitative Research in Accounting \& Management, Vol. 11 No. 4, pp. 380-415.

Cavalluzzo, K.S. and Ittner, C.D. (2004), "Implementing performance measurement innovations: evidence from government", Accounting, Organizations and Society, Vol. 29 Nos 3/4, pp. 243-267.

Chapman, C.S. (1997), "Reflections on a contingent view of accounting", Accounting, Organizations and Society, Vol. 22 No. 2, pp. 189-205.

Chenhall, R.H. (2006), "The contingent design of performance measures", in Bhimani, A. (Ed.), Contemporary Issues in Management Accounting, Oxford University Press, Oxford, pp. 92-116.

Chenhall, R.H., Hall, M. and Smith, D. (2010), "Social Capital and management control systems: a study of a non-government organization", Accounting, Organizations and Society, Vol. 35 No. 8, pp. 737-756.

Chua, W.F. (1995), "Experts, networks and inscriptions in the fabrication of accounting images: a story of the representation of three public hospitals", Accounting, Organizations and Society, Vol. 20 Nos 2/3, pp. 111-145. 
Eisenhardt, K.M. (1989), "Building theories from case study research", Academy of Management Review, Vol. 14 No. 4, pp. 532-550.

Ferreira, A. and Otley, D. (2009), "The design and use of performance management systems: an extended framework for analysis”, Management Accounting Research, Vol. 20 No. 4, pp. 263-282.

Franco-Santos, M., Lucianetti, L. and Bourne, M. (2012), "Contemporary performance measurement systems: a review of their consequences and a framework for research", Management Accounting Research, Vol. 23 No. 2, pp. 79-119.

Giovannoni, E. and Maraghini, M.P. (2013), "The challenges of integrated performance measurement systems: integrating mechanisms for integrated measures", Accounting, Auditing \& Accountability Journal, Vol. 26 No. 6, pp. 978-1008.

Hall, M. (2008), "The effect of comprehensive performance measurement systems on role clarity, psychological empowerment and managerial performance", Accounting, Organizations and Society, Vol. 33 Nos 2/3, pp. 141-163.

Hopwood, A.G. (1972), "An empirical study of the role of accounting data in performance evaluation", Journal of Accounting Research, Vol. 10, pp. 156-182.

Hoque, Z. and Chia, M. (2012), "Competitive forces and the levers of control framework in a manufacturing setting: a tale of a multinational subsidiary", Qualitative Research in Accounting \& Management, Vol. 9 No. 2, pp. 123-145.

Islam, S. (2016), "Reconceptualizing the notion of relations underlying performance measurement models: implications for research", Pacific Accounting Review, Vol. 28 No. 4, pp. 411-418.

Ittner, C.D. and Larcker, D.F. (2003), "Coming up short on nonfinancial performance measurement", Harvard Business Review, Vol. 81 No. 11, pp. 88-95.

Ittner, C.D., Larcker, D.F. and Randall, T. (2003), "Performance implications of strategic performance measurement in financial services firms", Accounting, Organizations and Society, Vol. 28 Nos 7/8, pp. 715-741.

Jönsson, S. and Lukka, K. (2007), "There and back again: doing interventionist research in management accounting", in Chapman, C.S., Hopwood, A.G. and Shields, M.D. (Eds), Handbooks of Management Accounting Research, Elsevier, Oxford, pp. 373-397.

Jordan, S. and Messner, M. (2012), "Enabling control and the problem of incomplete performance indicators", Accounting, Organizations and Society, Vol. 37 No. 8, pp. 544-564.

Jørgensen, B. and Messner, M. (2010), "Accounting and strategising: a case study from new product development”, Accounting, Organizations and Society, Vol. 35 No. 2, pp. 184-204.

Kaplan, R.S. and Norton, D.P. (2001), The Strategy-Focused Organization: How Balanced Scorecard Companies Thrive in the New Business Environment, Harvard Business School Press, Boston, Massachusetts.

Lillis, A.M. (2002), "Managing multiple dimensions of manufacturing performance - an exploratory study", Accounting, Organizations and Society, Vol. 27 No. 6, pp. 497-529.

Lohman, C., Fortuin, L. and Wouters, M. (2004), "Designing a performance measurement system: a case study", European Journal of Operational Research, Vol. 156 No. 2, pp. 267-286.

Lukka, K. and Vinnari, E. (2014), "Domain theory and method theory in management accounting", Accounting, Auditing \& Accountability Journal, Vol. 27 No. 8, pp. 1308-1338.

Malina, M.A., Nørreklit, H. and Selto, F.H. (2007), "Relations among measures, climate of control, and performance measurement models", Contemporary Accounting Research, Vol. 24 No. 3, pp. 935-982.

Merchant, K.A. (2006), "Measuring general managers' performances: market, accounting and combination-of-measures systems", Accounting, Auditing \& Accountability Journal, Vol. 19 No. 6, pp. 893-917. 
Merchant, K.A. and Van der Stede, W.A. (2012), Management Control Systems: Performance Measurement, Evaluation and Incentives, Pearson Education Limited, Harlow.

Mintzberg, H. (1978), "Patterns in strategy formation”, Management Science, Vol. 24 No. 9, pp. 934-948.

Performance measurement systems

Mintzberg, H. and Waters, J.A. (1985), “Of strategies, deliberate and emergent”, Strategic Management Journal, Vol. 6 No. 3, pp. 257-272.

Parker, L.D. and Northcott, D. (2016), "Qualitative generalising in accounting research: concepts and strategies”, Accounting, Auditing \& Accountability Journal, Vol. 29 No. 6, pp. 1100-1131.

Verbeeten, F.H.M. (2008), "Performance management practices in public sector organizations: impact on performance", Accounting, Auditing \& Accountability Journal, Vol. 21 No. 3, pp. 427-454.

Wouters, M. and Wilderom, C. (2008), "Developing performance-measurement systems as enabling formalization: a longitudinal field study of a logistics department", Accounting, Organizations and Society, Vol. 33 Nos 4/5, pp. 488-516.

\section{Appendix. Interview questions}

The interviews were semi-structured. Although general questions were prepared at the beginning, they were adapted based on responses.

(1) Strategy and strategic objectives:

- How do you define the strategy of your company?

- What are strategic objectives of the company? Please explain each of them.

- Would you explain when and how the strategy and strategic objectives were developed?

(2) Performance measurement system:

- Would you explain the performance measurement system (PMS) used in this company?

- What performance metrics do you measure in the PMS?

- How do you define each of these performance metrics?

- What equations are used for these performance metrics?

- Who were involved in the development of the current PMS?

- How did the current PMS emerge in the company?

- What is the main purpose of using the current PMS?

(3) Incompleteness of the PMS:

- To what extent do you think strategic objectives are measured by existing metrics? Please explain.

- Would you consider this problematic or non-problematic? Please explain.

- What actions do you take when you consider any instances problematic? Please explain.

- To what extent do you think existing metrics are aligned with strategic objectives? Please explain.

- Would you consider this problematic or non-problematic? Please explain.

- What actions do you take when you consider any instances problematic? Please explain.

- To what extent are you concerned about design qualities of the company's performance metrics? 


\section{QRAM}

- Would you consider this problematic or non-problematic? Please explain.

- What actions do you take when you consider any instances problematic? Please explain

(4) Concluding question:

- Would you like to elaborate on any issues related to strategy and the PMS of the company, which you think are important but not covered?

\section{Corresponding author}

Syrus Islam can be contacted at: syrus.islam@aut.ac.nz

For instructions on how to order reprints of this article, please visit our website: www.emeraldgrouppublishing.com/licensing/reprints.htm

Or contact us for further details: permissions@emeraldinsight.com 


\section{AUTHOR QUERIES}

\section{AUTHOR PLEASE ANSWER ALL QUERIES}

AQau-Please confirm the given-names and surnames are identified properly by the colours. =Given-Name, $\square=$ Surname

The colours are for proofing purposes only. The colours will not appear online or in print. 